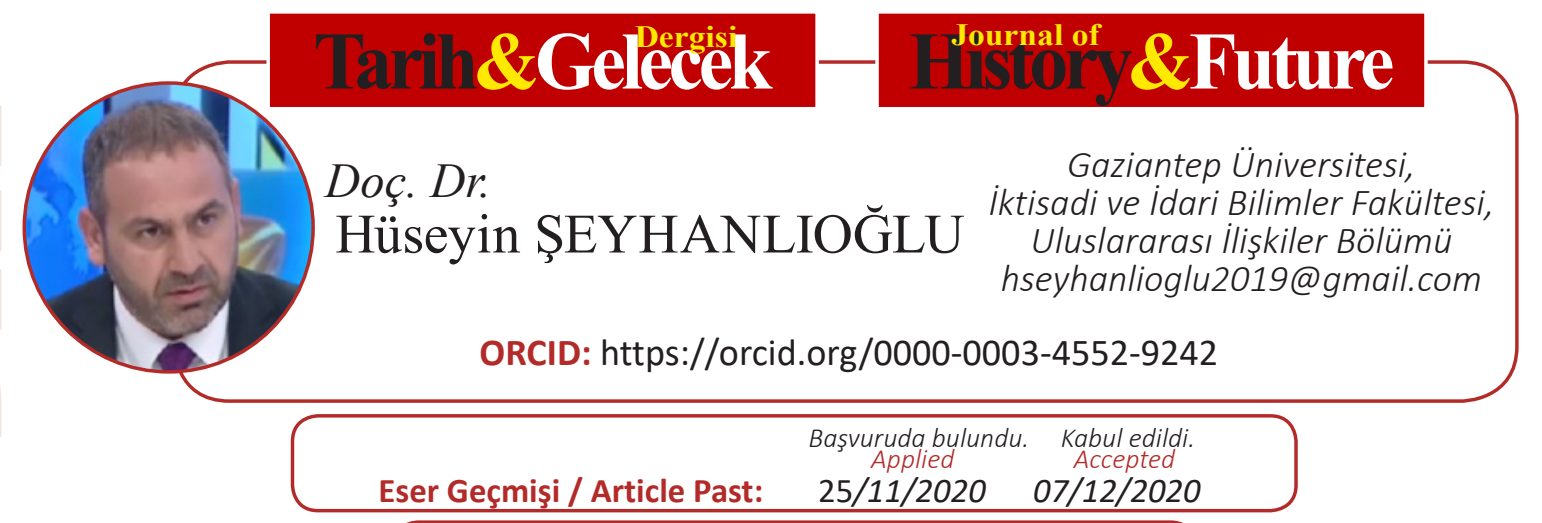

Araştırma Makalesi

DOI: http://dx.doi.org/10.21551/jhf.831072

Research Paper

Orjinal Makale / Orginal Paper

\title{
Demokrat Parti Döneminde Türkiye'de Kültürel Faaliyetler (1946-1960)
}

\author{
Culturel Activities during the Democrat Party in Turkey (1946-1960)
}

\section{$\ddot{O} z$}

Demokrat Parti (DP) kuruluşundan günümüze kadar Türkiye'nin siyasal hayatında, siyasi düşünce itibariyle mihenk taşı olarak kabul edilmektedir. Başta siyasal, sosyal ve kültürel alanlarda olmak üzere hem muhalefette hem de on yıllık kesintisiz iktidarından günümüze kadar derin etkilerde bulunmuştur.

1789 yılından itibaren başlayan ve zamanla, kendi ülkesinde psikolojik üstünlüğünü kaybeden Anadolu kültürünün, hem kültürüne yabancılaşmış yerli Batıcılara hem de mağrur Avrupa kültürünün yanında, II. Abdülhamit’ten sonra ilk kez kendi kadim kültürel kodlarıyla uyumlu ve siyasette biz de varız diyen bir iktidar olduğu görülmektedir.

DP'nin muhalefette iken, dönemin iktidarını kültür politikalarıyla değişime zorladı̆̆ı ve iktidara geldiği zaman ise ilk önce ekonomi ve kültürel değerlere yöneldiği görülmektedir. İlk icraat olarak ezanın Arapça okunması, Osmanlı hanedanına mensup kadınların sürgünden geri getirilmesi, Birecik köprüsünün açılması, İstanbul fethinin 500. yılı ve yeniden imarı, Yıldız seramik fabrikasının kurulması, Türk halk müziğinin ve Kur'an-1 Kerim’in radyolarda okunması... akla gelen ilklerdendir.

Tümevarım yöntemiyle elde edilen teorik kaynaklardan oluşan bu çalışmada DP'nin, Türk siyasal hayatı kültürel değerleri üzerindeki etkileri analiz edilmiştir.

Çalışmanın sonucunda, siyasal ve sosyal hayata Batı kültürünün yanına Anadolu kültürünü de getiren DP'nin, Anadolu halkının kültürel değerleriyle uyumlu çalışmalarından dolayı takdir edildiği, bugün bile en önemli siyasi değerlerden görüldüğ̈̈, isminin referans kaynağı olarak kullanıldı̆̆g görülmektedir.

Anahtar Kelimeler: DP, Kültür, Tarih, Ezan, Sanat 


\section{Abstract}

Democratic Party (DP) until today the establishment of Turkey's political life, is accepted as the cornerstone of political thought as. It has had deep effects both in the opposition and its ten-year uninterrupted power, up to the present, especially in the political, social and cultural fields.

Starting from 1789 and gradually losing its psychological superiority in its own country, the Anatolian culture, besides both the indigenous Westerners who were alienated from its culture and the proud European culture, II. For the first time after Abdülhamit, it is seen that there is a power that is compatible with its ancient cultural codes and says that we are also in politics.

It is seen that while DP was in opposition, it forced the power of the period to change with its cultural policies and when it came to power, it first turned towards economic and cultural values. the first practice is to read the adhan in Arabic, to bring the women belonging to the Ottoman dynasty back from exile, to open the Birecik bridge, the 500th anniversary of the conquest of Istanbul and to reconstruct the Y1ldiz ceramic factory, to read Turkish folk music and the Koran on the radio is one of the first to come.

In this study, which consists of theoretical sources obtained through induction method, the effects of DP on Turkish cultural life cultural values were analyzed. As a result of the study, it is seen that DP, which brought Anatolian culture to the political life as well as the Western culture, was appreciated for its harmonious works with the cultural values of the Anatolian people, it is seen as one of the most important political values and it is used as a reference source.

Keywords: DP, Culture, History, Azan, Art.

"Bugün Demokrat Parti resmen kuruldu. Şimdi Türk siyasî hayatında yepyeni bir sahife açılıyor. Bu tarih, gelecek kuşaklar için asla unutulmayacak bir kilometre taşı olacak. Artık tek parti-tek şef sisteminin egemenliği, yalnız devlet hayatımızın dar kalıpları arasından çıkmakla kalmayacak; aynı zamanda, milletimiz yıllarca özlemini çektiği demokrasinin en ufuklarından özgürce nasibini alacak. Ülkemizin kalkınmaya, ekonomik açıdan gelişmeye ihtiyacı var. Demokrasi ve kalkınma hamleleri Demokrat Parti'nin iki temel felsefesi olacak. Kurucusu olduğum bu partinin, politik hayatımızda sonsuza kadar devam edeceğini ümit etmek istiyorum. Bizden sonra bu partinin başına geçecek yöneticilerin, 1946 ruhunu daima hafizalarda canlı ve uyanı tutmalarl en samimi dileğimdir.” (Adnan MENDERES, 7 Ocak 1946)

\section{Giriş}

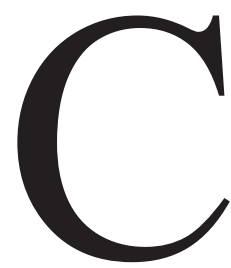
umhuriyet Halk Partisi'nin (CHP) yönetimindeki Türkiye, II. Dünya Savaşı'ndan sonra 27 yıllık tek partili antidemokratik siyasal yapının sürdürülemezliği, Sovyetler Birliği'nden gelen dış tehdidin büyüklüğü ve II. Dünya savaşının galip demokratik Batı ülkeleriyle yakınlaşmanın ön koşulu olarak görülmesi nedeniyle, ülke içinde demokratik açılımda bulunmak zorunda kalmıştır. Bunun siyasal karşılığı ise daha önce iki kez başarıl(a)mayan çok partili siyasal hayata geçiş olmuştur. 
Cumhuriyet döneminin ilk yıllarından itibaren iktisadi, sosyal ve siyasi sebeplerden ötürü bozulmuş olan halk ile yönetici kesim arasındaki ilişkinin düzeltilememesi, Serbest Cumhuriyet Firkası (SCF) ve Terrakiperver Cumhuriyet Furkası (TpCF) sonrasında tek partili siyasi hayatın problemlerinde bunalmış olan ve son olarak ise İkinci Dünya Harbi'nin ülke içerisinde oluşturmuş olduğu yeni bir toplumsal düzen ve talep arayışı - "toplumun sıkıntılarını ifade edeceği bir kanal araylşı" Türkiye'nin çok partili bir siyasi hayata geçmesinde zorunlu etmenler olmuştur.

Çok partili siyasi hayata geçiş ile ilgili Nihat Erim, İsmet İnönü'nün kendisine şu sözleri söylediğini ifade etmiştir:2

"Bizim şimdiki sistemimiz baştaki şahsa dayanmaktadır. Bu türlü idareler ekseriyetle pek parlak başlar, hatta bir müddet parlak devam eder. Fakat bunun sonu yoktur. Baştaki şahıs sahneden çekildiği zaman nasıl bir akıbetle karşılaşılacağı bilinmez. Tek parti rejimleri normal demokrasi usulleri ile idare şekline intikal edemedikleri, hiç değilse bu zaruri olan intikali tam zamanında yapamadıkları için yıkılmışlardır. Yıkıntının arkasından da birçok zahmetlerle meydana getirilen eserlerin hepsi heba olmuştur. Memleketimizi böyle bir akıbetten korumalıyız. Ciddi ve esaslı murakabe (seçim) sistemine sür'atle geçmeliyiz. Ben ömrümü tek parti rejimiyle geçirebilirim. Ama sonunu düşünüyorum, benden sonrasını düşünüyorum. Bu sebepten vakit geçirilmeksizin işe girişilmelidir."

Böylece, çok partili bir siyasal yaşama geçiş için iç ve dış şartlar olgunlaşmış ve bir kıvılcım beklenir hale gelmiştir. Bu kıvılcım ise toprak reformu kanunu olacaktır. Toprak reformu kanunu, aslında 1923 yılında Cumhuriyet'in kurulmasından hemen sonra düşünülmesine rağmen Mustafa Kemal Atatürk'ün son zamanlarında gündeme gelmiştir. Fakat Mustafa Kemal'in vefatı ve İkinci Dünya Harbi'nin araya girmesiyle birlikte bu husus bir daha gündem olamamıştır. "Topraksız Köylüye Toprak Dağıtılmasına ve Çiftçi Ocaklarının Kurulmasına Dair Kanun Tasarısı" isimli çalışma, 1945 yıllının Ocak ayının 17'sinde Türkiye Büyük Millet Meclisine sunulmuştur. Meclis Grup Başkan Vekilliğine 7 Haziran 1945'te önerge verilmiş ve 12 Haziran'da bu önerge görüşülmeye/tartışılmaya başlanmıştır. Fakat önergeyi (Takrir) vermiş olan isimler Cumhuriyet Halk Partisi (CHP) içerisinde bu önergenin kabul edileceğine ihtimal dahi vermemişlerdir. Önergeyi verenler arasında dikkat çeken isimlerden birisi olan Celal Bayar CHP grubunda bu önergenin kabul edilmesini; "eşyanın tabiatına aykırı" şeklinde ifade etmiş̧tir. Gerçekten de Takrir, partide firtınalar koparmıştır.

Sonuç olarak Dörtlü Takrir, mecliste reddedilmişse de Toprak Kanunu kabul edilmiştir. Takrir ve Kanun tartışmaları, 27 yıllık tek parti olan CHP içindeki muhalefetin, CHP'den ayrılmasını başlatan mekanizma olarak Türkiye'nin siyasal hayatında bir milat olarak yerini almıştır. Oysa işin gerçeğine bakılırsa Başar’a göre, “Takriri verenler, Halk Partisi'nden ayrılıp başka bir parti kurmak yerine, Halk Partisi'nde sslahat yaptırmak ve partiye hâkim olmak niyetindeydiler."’ Ancak Takrir, İsmet Paşa faktörü, CHP'nin bürokratik hegemonyası ve halk dilini konuşan dört kişinin halkta yoğun karşılık bulması nedeniyle, CHP içinde açılım yerine, Demokrat Parti'ye giden kuruluş

1 Şaban Sitembölükbaşı, Parti Seçmenlerinin Siyasal Yönelimlerine Etki Eden Sosyoekonomik Faktörler, Nobel Yayın Dağıtım, Ankara, 2001, s.114.

2 Rıfkı Salim Burçak, İdamların İçüzü, Demokratlar Kulübü Yayınları, Ankara, 1979, s. 52.

3 Ahmet Hamdi Başar, Yine Hayal Âleminde Uçuyorum, İstanbul Üniversitesi Yayınları, İstanbul, 2007, s.50. 
sürecinin ilk kilometre taşı olarak görülmektedir.

\section{Demokrat Parti’nin Kuruluşu ve Kültür Stratejisi}

Aralık 1945 yılına gelindiğinde artık DP kurulabilirdi. CHP’nin içinden Bayar, Menderes, Köprülü ve Koraltan üzerinde dört temel direği bulunan, TpCF ve SCF'nin CHP'den bıkarcasına nefret eden ve "Yeter! Söz Milletindir" diyen muhafazakâr bir halk taban1, aklı tek parti döneminin ebedi ve değişmez genel başkanlıği ruhunda olsa da, değişen iç ve diş şartlar nedeniyle, mecburi rota demokratik Batılı ülkelerin hâkimiyetinde yeni bir dünya düzeni vardı. Dolayısıyla iç ve dış şartlar, CHP'ye yolun sonuna geldiğini gösterirken, DP'nin önüne kırmızı halılar sermiştir.

DP'nin tüm seçim çalışmalarında ve CHP'yle mücadelesinde, Türkiye'nin içinde bulunduğu ağır ekonomik şartlardan ziyade, halkın başta ezan olmak üzere dini ve halk müziği gibi kültürel baskılarından kaynaklandığı görülmüştür. Örneğin, ünlü halk ozanı Aşık Veysel bile, köylü kıyafetlerinden dolayı Ulus Meydanından atılmış ve sazı kırılmıştı.

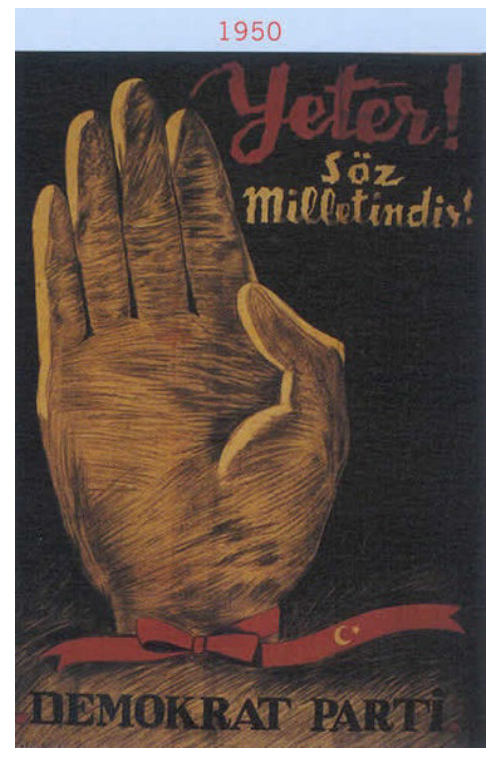

(Türkiye siyasal hayatının en önemli afişlerinden birisi) ${ }^{4}$

Demokrat Parti'nin seksen sekiz (88) maddelik programı, Genel Hükümler ve Hükümet İşleri başlıkları ile iki bölüme ayrılmıştır. Demokrat Parti'nin kültür politikası ve CHP üzerindeki etkileri bakımından aşağıdaki maddeler önemli görülmektedir5:

"Yurttaşlar arasında müşterek bir tarihin yarattığı kültür ve ülkü birliğine dayanan ve her türlü ayırıcı temayülleri reddeden bir milliyetçilik telakkisine bağlıyı. Partimiz, bütün yurttaşları din ve 1rk farkı gözetmeksizin, Türk sayar ve Türk olmanın bütün haklarına sahip tanır. Kanunî vazifelerini yerine getiren her ferde iyi bir yurttaş gözüyle bakarız. Bu ana görüşlerin tatbikatta yer bulmasına dikkatle çalışacağız. Eğitim ve öğretim müesseselerimizi böyle bir milliyetçilik idealinin tahakkukunda vazifeli saymaktayız. (13. Madde)"

4 Hüseyin Şeyhanlığlu, Türkiye'nin Siyasal Hayatında Demokrat Parti, Kitapyurdu Doğrudan Yayıncılık, istanbul, 2020

5 Hüseyin Şeyhanlığlu, Türkiye’nin Siyasal Hayatında Demokrat Parti, Kitapyurdu Doğrudan Yayıncılık, İstanbul, 2020, s.85. 
"Partimiz laikliği devletin siyasette dinle hiç bir ilgisi bulunmaması ve hiç bir din düşüncesinin kanunların tanzim ve tatbikinde müessir olmaması manasında anlar ve laikliğin din aleyhtarlı̆̆ hürriyetler gibi insanlığın mukaddes haklarından tanır.Gerek dinî tedrisat meselesi ve gerekse din adamlarını yetiştirecek müesseseler kurulması hususunda mütehassıslar tarafından esaslı bir program hazırlanması zaruridir. Üniversite içinde yer alacak İlahiyat Fakültesi ve ilmî mahiyette mümasil müesseseler, Millî Eğitim Bakanlı̆̆ı'nın bu kabil müesseseleri gibi muhtar olmalıdır. Dinin siyaset aleti olarak kullanılmasına, yurttaşlar arasında sevgi ve tesanütü bozacak şekilde propaganda vasıtası yapılmasına, serbest tefekküre karşı taassup duygularını harekete getirmesine müsamaha olunmamalıdır. (14. Madde)"

Özetle, on üçüncü maddede, kültür ve ülkü birliğini hedefleyen, vatandaşları birleştiren pozitif milliyetçilik ve muhafazakârlığın temel ilkelerinden olan DP'nin düzen ve otorite anlayışının kanun ve geleneksel değerlere itaat olarak belirtildiği görülürken; on dördüncü maddede ise DP'nin din üzerindeki baskıların kaldırılmasını, dini denetleyen ve düzenleyen CHP'nin “militan laiklik" anlayışına karşı, din hürriyetinin diğer hürriyetler gibi bir hürriyet olduğunu savunduğu, pozitif laikliği ve bu düşünceyle modern dinî eğitim kurumlarının kurulmasını savunduğu görülmektedir.

\section{DP'nin CHP Üzerindeki Kültürel Etkileri (1946-1950)}

CHP, DP'nin kurulmasından sonra 27 yıllık devlet-parti bütünlüğünün vermiş olduğu rahat alanı terk etmek zorunda kalmıştır. Bunun sonucu olarak II. CHP Kurultayının yapıldığı 10 Mayıs 1946'da,CHP yöneticileri bu duruma karş1 yeni politikaların geliştirilmesi gerektiği hususunda görüş birliğine varmışlardır.

CHP’nin II. Kurultayında öncelikle “değişmez genel başkanlık kaldırılmış, bunun yerine dört yıllık süreler için partili milletvekilleri içinden ve Büyük Kurultay tarafından seçilmesi kararına bağlı değişebilir genel başkanlık sistemi getirilmiş, tek dereceli seçim usulü benimsenmiş, sınıf esasına dayalı dernekler ve örgütler kurulabileceği kabul edilmiş̧ir"’6.

Özellikle halkın yoğun talepleri arasında yer alan Arapça ezan ve dini değerlerin yaşanılması talepleri CHP'yi bu konuda katı laiklikten vaz geçmek zorunda bırakmıştır. Bu amaçla din ile ilgili yapılmış olan faaliyetlerin halk nezdinde, CHP lehine olumlu bir yarar sağlanabilmesi için "Türkiye'de İslâm Dini Tedrisatı" başlığıyla Son Telgraf Gazetesinin ºaş sayfasında yer almıştır. $\mathrm{Bu}$ habere göre, CHP bu yeni sürece göre halkın taleplerine göre pozisyonunu belirlemeye çalışmaktadır.

17 Kasım 1947'de toplanan CHP'nin III. Kurultayında bu konuda somut adımlar atıldığı görülmektedir. Çünkü açık oy ve gizli sayım olmasaydı CHP bir yıl önceki seçimleri kaybedebilirdi ki İstanbul'da bakanlar bile seçimleri kaybetmişti. Bu nedenle, CHP'nin ideolojisi ve programı bu Kurultay'da devrimciolmaktançıkartılıpdaha 11 ımlıbirdurumagetirilmiştir. Sosyal konulardaortanın sağında yer alan Kurultay, Halkevleri ve Köy Enstitülerinin çalışma standartlarını değiştirmiştir. Parti tüzüğünde önemli değişiklikler yapılarak illerde CHP il başkanlarının vali olmaları hususuna son verilmiş ve parti genel başkanlığ ile cumhurbaşkanlığı birbirinden ayrılmıştır. Örneğin, CHP

6 Rahmi Kumaş, CHP’nin Soyağacı, Çağdaş Yayınları, İstanbul, 1999, s. 47-48

7 Son Telgraf Gazetesi, 3 Temmuz 1947 
bu kurultayda laikliğin tanımlamasını da değiştirmiştir. 1935’te CHP programında laiklik; “dinî düşünceleri dünya işlerinden ve siyasetten ayrı tutmak" şeklinde tanımlanırken; III. Kurultayda (1947) ise "siyaset” kelimesi çıkartılarak kavram, "din ve devlet/dünya işlerinin birbirinden ayrı olması” şeklinde değiştirilmiştir. Aynı şekilde Diyanet İşleri Başkanlığının bütçesinde 1947'nin Aralık ayında önemli bir miktarda artışa gidilmiştir. Diyanet İşleri Başkanlığının murakabesi ile bir dergi çıkartmasına karar verilmiştir. 1948'in 11 Şubat'ında İmam Hatip okullarının açılması için, CHP bir komisyon kurmuştur. Yine şubat ayında CHP'li Fatih Gökmen İmam Hatip okullarının açılması için kanun teklifi vermiştir ve bu kanun teklifi CHP grubunda görüşülmüştür.

1949’da Urfa, Trabzon, Seyhan, Kastamonu, Isparta, İzmir, İstanbul, Afyon ve Ankara’da imam hatip kursları açılmıştır. Bu kursların ortaokula eşdeğer olan iki yıllık meslek okulları haline gelmesine Milli Eğitim Bakanlığınca karar verilmiştir. 1949'da ise ilkokulların 4 ve 5. sınıflarında din dersleri okutulmaya başlanmış ve 30 Şubat'ta ise İlahiyat Fakültelerinin açılması için kanun hazırlanmıştır.

Ayinlerin ve ibadetlerin rahatça yapılması, dini ve tarihi büyüklerin türbelerinin ziyarete açılması, ders programlarına seçmeli din derslerin konulması, haftada bir saatlik de olsa iyi bir başlangıç sayılırdı. CHP yönetimi, CHP'nin din eğitimine önem verdiğini gösteren bir maddenin parti programına eklenmesi ve yeniden İlahiyat Fakültelerinin ve İmam Hatip Ortaokullarının açılması için karar almıştır ${ }^{8}$.

Tekke ve zaviyelerin kapatılmasına dair kanunda değişikliğe gidilerek bazı türbeler de ziyarete açılmıştır. Örnek olarak 21 Nisan 1950'de Yavuz Sultan Selim'in Türbesi halka açılmıştır. Aybar'a göre", “Allah'ın adını asla sebepsiz yere anmayan kararlı bir laisist olan İn̈nü ve CHP, bugüne kadar devrimciliği ve laikliğiyle övünen bu parti (CHP) selameti, hayatının en kritik döneminde dini kucaklamakta bulmuştur”.

Kısaca CHP özellikle dini alanda başta olmak üzere kültürel alanda kapsamlı açılımlarda bulunmakta ve altı oktan ciddi sapmalar göstermekteydi.

\section{Demokrat Parti İktidarında Kültürel Faaliyetler (14 Mayıs 1950 - 27 Mayıs 1960)}

Hâkim teminatı olmaksızın sonuçların jandarma eşliğinde sandık depolarında yakıldığı, açık oy ve gizli sayımla yapılan 1946 seçimleri sayılmazsa 14 Mayıs 1950'deki DP'nin seçim kampanyası esas olarak iki temel üzerine inşa edilmiştir. Bunlardan birisi ekonomi diğeri ise CHP'nin başta din olmak üzere kültür üzerindeki baskısıyla ilgilidir.

DP, tüm seçim çalışmalarında din özgürlügünü güvence altına alacağına söz vermiştir.Bu konuda özellikle Adnan Menderes, kesin konuşmuştur. İkinci durum ise devletin ekonomi üzerindeki müthiş denetimiyle ilgili olmuştur. DP, iktisadi alanda devlet müdahalesinin azaltılacağını, köylünün emeğinin tam karşılığını vereceğini, devlete ait işletmeleri özel sektöre aktaracağını, tutucu ve bürokratik devlet anlayışının tasfiye edileceğini, özel sektörün destekleneceğini, batı demokrasilerinin örnek alınacağını, siyasî rejimin demokratik bir zihniyetle yeniden düzenleneceğini, milletin esas alınacağı ve sadece millete mal olmuş devrimlerin korunarak son sözün millete ait olacağını vurgulamıştır.

8 Ali Eşref Turan, Türkiye’de Seçmen Davranışı Önceki Kırılmalar ve 2002 Seçimi, Bilgi Üniversitesi Yayınlar1, İstanbul2004, s. 27.

9 Feroz Ahmad, Modern Türkiye’nin Oluşumu, Sarmal Yayınları, İstanbul 2005, s. 154. 
DP'nin CHP karşısında yükselmesini sağlayan esas husus da burada görüldüğünü hatta kültüre olan vurgu ve kabulün ekonomiden önce geldiğini söyleyebiliriz.

Çünkü bu anlamda ismi gibi demokrat olduğu ve liberal bir yapıya sahip olmasıyla halka güven ve umut verdiği görülmüştür. Böylelikle yeni oluşan değerler sisteminin muhafazakâr dinamiği, o dönemin siyasi ve bürokratik merkezi olan CHP'den uzaklaşmış ve çevre partisi olan DP gibi gelenekçi-liberal bir tercih yapmıştır.

Seçim çalışmalarında DP ve meydanlarda halk, CHP'yi öylesine sıkıştırıyordu ki CHP seçim süresince, tekrar seçilmesi halinde varlık sebebi olarak gördüğü "Kemalizm'in altı ilkesi”ni bile anayasadan çıkarmayı vaat etmişti. Buna karşılık olarak DP ise halka, "Kurnaz Tilki” İsmet Paşa'nın ülkenin başında kalması halinde hiçbir şeyin değişmeyeceğini, " $C H P$ ve Devletin birbirinden farklı (şeyler) olduğunu" ${ }^{10}$ söylüyordu. Seçim çalışmalarında, halk, sandığı sadece parti değişikliği değil esas olarak reyimiz namusumuz ve hak-batıl savaşı olarak görmüştü.

14 Mayıs 1950 ertesi günlerinde kesin açılanan seçim sonuçlarına göre DP, ezici bir başarı sağlamış ve CHP iktidarı kaybetmiştir. Uzun süredir beklenen ancak kısa süren seçim çalışmalarından sonra Demokrat Parti'nin iktidara gelmesi birbirinden çok farklı kesimler için tarihî bir dönüm noktası, "kansız bir ihtilâl' meydana gelmiş ve CHP, iktidarı askeri desteğe rağmen

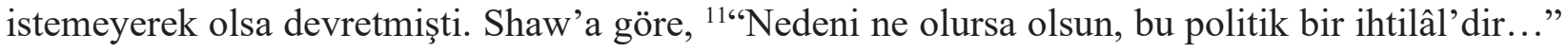
"Bu, 1909 yılından beri devletin ve milletin hayatına çökmüş, ismi değişmiş de olsa aynı olan bir zihniyetin seçim yoluyla iktidardan indirilmesi olarak görülmüştür. ${ }^{12}$

"1950 Türkiye'sinde hem de normal seçimler yolu ile sular dalgalandı. Suların dibinden suların yüzüne yeni insanlar yeni davalar çıktı. Evet, yeni insanlar ve yeni davalar. 1923’ten beri süre gelen nizam-1 âlem başka bir nizam-1 âleme döndü. Bu bir ihtilâl mi idi? Bu inkılâp mı idi? (...) Bu seçim zaferine derhal geniş manalar verdiler: Beyaz İhtilâl... Bütün inkılâpların en önemlisi 14 Mayıs İnkılâbı'dır! Eh! Gidenler de ihtilâller, inkılâplar yolu ile gelmemişler miydi? (...) 14 Mayıs 1950 seçimlerinde Türkiye'de olan acaba bir Beyaz İhtilâl miydi? Sanıyorum ki evet..."

2 Haziran'a kadar süren hükümet çalışmalarının ilkinde, Adnan Menderes hükümetinin programı üzerinde elliden fazla milletvekili söz alarak konuşma yapar. Konuşmaların özünü, Allah'a şükür, halka teşekkür ve az daha sabır oluşturuyordu. Seçimle geldiklerine göre her şeyi artık yapabileceklerini düşünüyorlardı. Ne de olsa demokrasinin özü halktı ve halk da DP'yi iktidar yapmıştı. Oysa bundan sonraki iki seçimi de kazanan DP, asla muktedir olamayacaktı. $\mathrm{Bu}$ vekiller tıpkı I. Kongre'de olduğu gibi uygun gördükleri her konuda açıkça konuşmuşlardır. Örneğin, Ankara Milletvekili Sadri Maksudi Arsal konuşmasında ${ }^{13}$ Memlekette ırkçıllk diye bir tehlike bulunmadığını, ayrıca ırkçılık ile milliyetçiliğin karıştırılmamasını, kendisinin de koyu bir milliyetçi olduğunu" bu nedenle programda "komünizm ve gericilik" ile mücadele edilmesi yolunda bir cümlenin yeterli olacağını belirterek, "irkçılık" ile ilgili kısmın programdan çıkarılmasını isterken; Antalya milletvekili Burhanettin Onat "Müslüman ülkelerle daha sıkı bir işbirliğine

10 Feroz Ahmad, Modern Türkiye’nin Oluşumu, Sarmal Yayınları, İstanbul 2005, s. 155

11 Standford JShaw ve Ezel Kural Shaw,Osmanlı Imparatorluğu ve Modern Türkiye. Cilt II, E Yayınlar1, İstanbul 1983, s. 477.

12 Şevket SüreyyaAydemir, İkinci Adam. Cilt III, Remzi Kitapevi,İstanbul 1968.s. 14.

13 DPMGMZ, 1950, s. 26. 
gidilmesi, Arap Dünyasının Türklere karşı büyük sevgi beslediğini, oysa Başbakan Menderes'in bu devletlerle ilgili olarak söylediklerinin "biraz muğlâk biraz gayr-i kâfi" olduğundan şikâyet etmiş ve bu ülkelerle; "aradaki gümrüklerin kalkması, orduların bir elden bir sisteme tâbi olarak idare edilmesi gerektiğini ve nihayet bir müşterek şark devletleri parlamentosu toplanarak, haricî siyasetin de bir elden idare edilmesi gerektiğini belirtmiştir.

Şevki Yazman (Elazığ milletvekili) ise konuşmasında bürokratik zihniyeti eleştirmiş, dinî konularda fiilî sınırlamaların mevcut olduğunu, bu hususların kaldırılması gerektiğini ifade ettikten sonra "Biz ezanı ilahiyi Türkçe okumaya neden mecbur olalım? Eğer topluluk ezanın Türkçe okunmasını istiyorsa Türkçe, Arapça okunmasını istiyorsa Arapça okuyalım. Milyonlarca laik Avrupalı duasını Latin dilinde dinler veya okur... Onlarda laiklik elden gitmiyor... Kıyafet kararnamesinde de garip vaziyetler vardır. Sarığı ve fesi hiç hatırınıza getirmeyiniz amma 20-25 seneden beri herkesin kafasında taşıdığ 1 kasket berbat bir hale gelmiştir" ${ }^{14}$.

DP'nin hükümet programı, oylamaya katılan 245 kişinin oy birliğiyle güvenoyu almıştır. Başbakan Adnan Menderes ise yaptığı konuşmada şöyle der: "Tarihimizde ilk defadır ki yüksek heyetiniz millî iradenin tam ve serbest tecellisi neticesinde millet mukadderatına hâkim mevkie gelmiş bulunmaktadır". ${ }^{15}$

CHP lideri İsmet İnönü’nün DP’ye ilk tepkisi ise “Diktatörlüğe gidiyorlar, ölünceye kadar çarpışacağım, aydın gençliği bu olayı kınamaya çağırıyorum” ve "DP'yi şiddet yolunda olmakla suçlamıştır1' ". Daha bir günlük iktidara karşı CHP'nin bu bakış açısı ve siyasî taktiğinin 10 yıl boyunca hiç değişmediği görülecektir. Özetle DP artık halka sırtını dayamış, iktidarı kansız devralmış ve bu, o güne kadar kimseye nasip olmamış kitlelerin duruşuydu.

DP yöneticileri ve Adnan Menderes seçim kampanyaları sürecinde ezanın yeniden Arapça okunması talebinin halktan kendilerine gelen en büyük taleplerden birisi olduğunu belirtmişlerdir. Menderes ezanın Arapça okunmasına karşı olan bu yasağın anlamsız ve laikliğe da aykırı olduğunu belirterek bu durumun görüşülmesi için konuyu 13 Haziran'da DP Grubuna göndermiştir. DP Grubu aynı gün, Ceza Kanununun 526. maddesinden "Arapça ezan okunması ve kamet kelimesi hakkında takyidin de kaldırılması suretiyle istenildiği gibi okunması için gerek hükümet tarafından getirilecek tasarının gerekse arkadaşlar tarafindan getirilecek tekliflerin kabul edilmesini oy birliğiyle ve alkışlarla kabul etmiştir.

Grup kararından sonra Ahmet Gürkan (Tokat Milletvekili), İsmail Berkok (Kayseri Milletvekili) ve 16 kişinin hazırlamış olduğu yasa tasarısı TBMM'ye Haziran'ın 16'sında sunulmuştur. Bu tasarı DP ile birlikte CHP'den de önemli ölçüde bir destek görmüştür. Barutçu'ya göre "Meclisin neredeyse tamamına yakını ezanın Türkçe okunmasının bir yanlış/hata olduğunu itiraf edecek duruma geldiğini, DP’nin önerisinin özlemle onaylamaya karar vermişlerdir ${ }^{17}$.

14 DPMGMZ, 1950, s. 28.

15 TBMMTD, 1950, s. 26-30.

16 Rıfkı Salim Burçak, Yassıada ve Öncesi, Çam Matbaası, Ankara 1977,s. 440.

17 Rıfkı Salim Burçak, Yassıada ve Öncesi, Çam Matbaası, Ankara 1977, s. 443. 


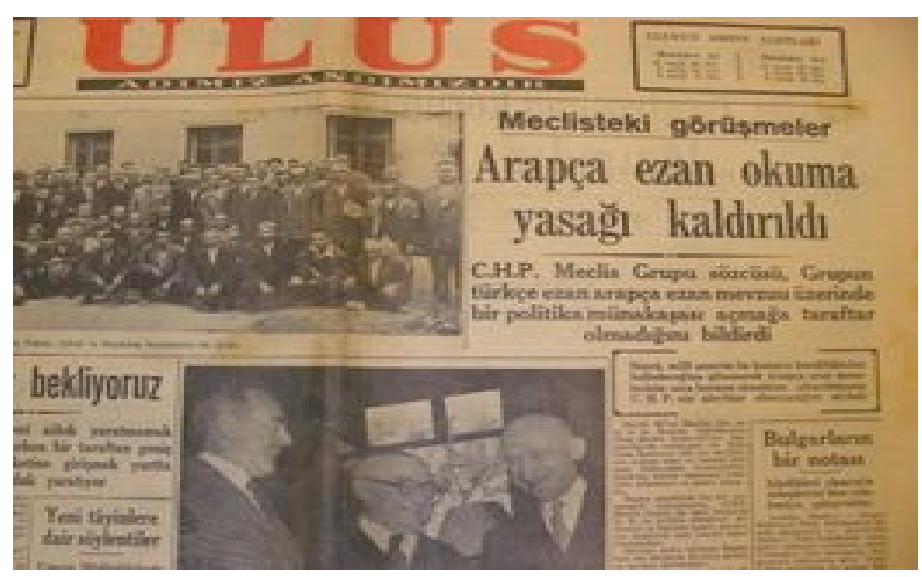

DP'nin iktidara gelmesinden 15 gün sonra toplumun üzerinde büyük uzlaşıyla beklediği “Arapça ezan ve kamet okuma yasağının kaldırılması” basına geniş ölçüde yansımıştır. İnönü’nün damadı ve DP'ye muhalif gazetecilerin başında gelen Toker'e göre ${ }^{18}$ "Menderes, bunu ulusa mâl olmamış devrimlerden" saymıştı. Bu kanunun çıkması DP tarihinde halk arasında yaygın olarak kabul edilen ve en çok konuşulan uygulamalardan birisi olmuştur. Aydın Menderes'e göre "Müslüman ülkeler arasında aslına uygun ezan okumayan tek ülke olan Müslüman Türkiye, bu ayıptan da kurtulmuş oluyordu"19.

DP halkın düşünce ve taleplerine uygun olarak büyük destek gören İstanbul ve Ankara radyolarında, her pazartesi, çarşamba ve cuma günleri tanınmış hafızlar tarafından Kur'an okunması uygulamasını da başlattıktan sonra İlkokulların 3, 4, ve 5. sınıflarına din dersi konulması, dinî eğitim veren okulların açılmasına karar verilir.

DP'ye göre Köy Enstitüleri, birer misyoner okulu gibi çalı̧̧makta ve halkı dinden, ahlâktan, bilimden uzaklaştırmaktadır. 1955 yılı, Menderes ve hükümetinin geçireceği en zor yıl olarak tarihe geçmiştir. Menderes 13 Ekim'de Trabzon'da yaptığı seçim mitinginde şöyle der:

"İsmet Paşa buhran diyor. Buhran, Paşa'nın kafasındadır. İsmet Paşa hastadır. Malta humması, Asya gribi gibi bir hastalığa tutulmuştur. Onun hastalığının adı dar-ül iktidardır." ...(Bir gün sonra Giresun) "İsmet paşa hayatının hiçbir devrinde bir gün dahi, vatandaşın serbest reyi ile işbaşına gelmiş değildir. İlk serbest seçim yapıldığı gün de iş başından uzaklaştırılmıştır. (...) İmam hatip mekteplerini biz açtık, derler. Bu okulların sayılarının bugün 18 'e vardığından haberleri yok galiba... Türk milleti Müslüman'dır, hatta başka memleketlerdeki Müslümanlardan çok daha hulus ile çok daha sâfiyane ve hurafeden azade olarak dinine bağlıdır. Bu memlekette cami inşa etmenin bile kusur telakki edildiği zamanlar oldu. Bir hoca görüldüğü zaman hürmet etmek, itibar etmek gerekirken onunla alay etmek, o devrin âdeti haline gelmişti. Bir kanuna dahi dayanamadan ezanın Türkçe okunması mecburi hale getirilmişti."

Başbakan Menderes, "halkın benimsediği devrimleri biz de benimsiyoruz ama halkın benimsemediklerini de kaldıracaklarını” belirttiği konuşmasında DP'nin devrimlere bakışını şöyle

18 Metin Toker,Demokrat Partinin Altın Yllları (1950-1954), Ofset Tipo Matbaac1lık, Ankara 1990s. 51.

19 Hüseyin Şeyhanlığlu, Türk Siyasal Muhafazakârlığının Kurumsallaşması ve Demokrat Parti, Ankara: Kadim Yayınlar1, Ankara 2011, s. 122. 
ifade etmiştir ${ }^{20}$ :

Millete mâl olmamış, millet vicdanına (bir) değirmen taşı ağırlığıyla çökmüş olan bazı tedbirleri ortadan kaldıracağız. Millet vicdanına baskı yapmakta olan birtakım tedbirleri, 15 - 20 sene sonra üzerinde bekçi gibi duracağı, onları mutlaka muhafaza edeceğiz demek doğru mudur? Seçim beyannamemizde yazıldığı üzere (sadece) millete mâl olmuş inkılâplarımızı mahfuz tutacağız.

Lewis’e göre halk, İstiklâl Marşı'nın yazıldığı Taceddin Dergâh'ına gidip, “Allah, bu milleti Allah'sız CHP'den kurtarsın” diye dua ediyordu ${ }^{21}$. Bundan ötürü DP'nin din politikaları irdelenirken/analiz edilirken CHP'nin "militan laiklik" olarak tanımlanan laiklik anlayışına karşı DP'nin laiklik yorumu analiz edilecektir. Aydın Menderes'e göre “Müslüman ülkeler arasında aslına uygun ezan okumayan tek ülke olan Müslüman Türkiye, böylece bu ayıptan da kurtulmuş oluyordu.” Bu uygulama hiç şüphesiz DP adının din ile birlikte bir parti olarak günümüze kadar anılmasını sağlayacaktır.

7 Temmuz'da, Ankara ve İstanbul radyolarında her pazartesi, çarşamba ve cuma günleri tanınmış hafızlar tarafından Kur'an okunmasına başlanmıştır. Aynı zamanda İlkokulların 3, 4 ve 5. sınıflara din dersi konulması, dinî eğitim veren okulların açılmasına karar verilmiştir. Aynı şekilde, 14 Temmuz 1950'de Fatih Sultan Mehmet'in Türbesi ziyarete açılmıştır, Ağustos 1950'de, Deniz Müzesi olarak kullanılmakta olan Dolmabahçe Camii'nin halka açılmasına karar verilmiş ve 1 Eylül'de de Eyüp Sultan türbesi ziyarete açılmıştır.

$\mathrm{Bu}$ dönemde en etkili kitle iletişim aracı olan radyonun, Rusya ve Batılı ülkeler tarafından ciddi bir propaganda arac122 olarak kullanılmasına rağmen, halk Ankara Radyosu yerine Moskova Radyosu, Doğu Anadolu'da Erivan Radyosu, BBC'ye hatta Arap radyolarına kulak kabartıyordu. Bunu, DP'nin iktidara gelmesinden hemen sonra yapılan şikâyetlerin birinde görmek mümkündür: "İki radyo istasyonumuzun (Ankara ve İstanbul) açılışından kapanışına kadar hiç olmazsa sıra ile birinde Türk musikisi bulabilir miyiz? Sevmediğimizi zorla dinleyemiyoruz. Radyoyu kapatmaktan ve Arap kanalları aramaktan kurtarınız." Bunun gibi onlarca şikâyet mektubuna rağmen DP döneminde bile radyoda halk müziği oranı ancak \%60'a çıkabilmiştir.

3 Aralık 1950 tarihinde, Arap harfleriyle tedrisat ${ }^{23}$ yapmak için gizli ya da aleni dershane açanlar hakkında 23 Eylül 1931 günlü 12073 sayılı kararnamedeki yasaklama kaldırıldı ve böylece Kur'an kurslarının önü açıldı. Çünkü bu dönemde Kur'an okumak ve okutmak yasaktı. Halk

20 Mükerrem Sarol, Bilinmeyen Menderes, Kervan Yayınlar1, Ankara 1983, s. 238.

21 Bernard Lewis, Modern Türkiye’nin Doğuşu, Arkadaş Yayınları, Ankara 2009, s. 448.

22 Hüseyin Şeyhanlıŏlu, Radyonun Demokratik Yaşamda ve Siyasetteki Etkisi: Demokrat Parti Dönemi (1950-1960), 2019,s. 805.

23 1940'ların başında Ankara Hacı Bayram-1 Veli Camii civarında yaşayan bir hocaya, CHP’nin Çankırı ilçe teşkilatından bir zat gelir. Bu zatın talebi, tarlasına musallat olan farelerden kurtulmaktı. Ancak DDT’nin olmadığı bir zamanda, muskadan başka çaresi kalmadığını düşünmüş ve hocadan bir muska yazmasını, zor bela rica etmişti. Hoca yazamayacağını, Arap harflerinin yasak olduğunu belirttiyse de CHP'li adamdan yakasını kurtaramaz. Nihayetinde bir kâğıda Osmanlıca bir şeyler karalayan hoca, bunun bir fare deliğine konulmasını ister. Dediği gibi muskayı tarladaki fare deliklerinden birine koyan adam, 15 gün sonra tarlayı kontrole gider ve farelerden eser kalmadığını hayretle görür. Adam soluğu hocanın yanında, 1 kilo leblebiyle alır. Ve Allah için rica eder... Hocam kâğıda ne yazdınız? Hoca, kulağına eğilerek aralarında sır kalması koşuluyla, CHP ilkelerine yemin etmesi şartıyla mecburen şöyle cevap verir: "Ey fareler! Bu tarlayı derhal terk edin. Çünkü burası bir CHP’linindir”. 
cenazelerini gece defnederdi. 1942'de gazete ve dergilerdeki her türlü dinî yayın yasaklanırken CHP iktidarının son demlerinde (1949) on ay süreli on merkez ilde imam hatip kursları açılmıştır. DP döneminde ise bu kurslar İmam Hatip Okullarına dönüştürülmüştür.

1950'de ülke genelinde 7 tane İmam Hatip Ortaokulu mevcuttu. 1960 y1lında ise okul sayıs1 19 olmuştur. Kur'an Kurslarının sayısı ise 1950 'de 237,1960 'da ise 1117 'ye ulaşmıştır ${ }^{24}$. Bu dönemde dini derneklerin tüm derneklerin yaklaşık üçte birine denk geldiği ifade edilmektedir. Milli Eğitim Bakanı Tevfik İleri, din eğitimi konusundaki düşüncelerini şu şekilde izah etmiştir:

"İlkokul çocuğu terbiye ve telkin çağındadır. Çocuk, dini de ancak telkin yoluyla öğrenecektir. Binaenaleyh çocuk, Allah ve peygamber vardır diye öğrendiği bu ilk bilgiyi bütün ömrü boyunca unutmayacaktır. Hâlbuki liseye gelip de kozmografya, astronomi, fizik okuyan bir öğrenci Allah var diye inanmıyorsa veya inanıyorsa artık onun fikrini değiştiremezsiniz (...) Aynı tahsili yapmış ve aynı kudrette iki gençten biri namaz kılsa oruç tutsa diğeri bunları yapmazsa ve aksine boş zamanlarında içki içse ve kumar oynasa, soruyorum bunların hangisi memleket için daha faydalıdır. Yazık... Truman, Churchill vb... din adamlarının önünde diz çöker, el öper... Yobaz olmaz... Fakat bizde dinden ve din lafindan, Allah adından, vebadan korkar gibi korkulur... Kızılların ekmeğine yağ sürmeye hakkımız yoktur."

DP iktidara geldikten sonra Diyanet İşleri Başkanlığı aracılığıyla dini yayınlarda birçok yeni eser bastırmıştır. Bu dini eserlerin basılmasıyla toplumda farklı bir tutum ve davranış ortaya çıkmıştır. Zürcher toplumdaki bu psikolojik havayı şu şekilde ifade etmiştir ${ }^{25}$ :

"DP döneminde laiklik politikalarının gevşetilmiş olması, muazzam kentleşme olgusu yüzünden kırsal kesim kültürünün daha da hissedilir hale gelmiş olduğu kentlerin günlük yaşamının içinde, İslâm'ı çok daha belirgin hale getirmişti. Türk aydınları o zaman - ve sonraları - bunu İslâm'ın dirilişi olarak algıladılar ama her ne kadar faaliyet gösteren köktenci topluluklar varsa da İslâm'ın dirilişi denilen şey aslında yalnızca halk kitlesinin yaşamaya devam eden geleneksel kültürüydü; eskinin bağımlı sınıfı kendini ifade etme hakkını yeniden israrla savunuyordu."

Dini alanda DP'nin yaratmış olduğu bu olumlu havanın dini eğilimli şiddet hareketlerini de motive ettiğini söylemek mümkündür. Millî Eğitim Bakanı Tevfik İleri’nin 16 Ekim 1957'de Samsun'da yapmış olduğu seçim konuşmasında, DP'nin 15 bin camiyi 7 yılda yaptıklarını, 17 İmam Hatip Okulunu eğitime kazandırdıklarını, din adamının yetiştirilmesi için yeni okulların açılacağını ifade etmiş̧ir. Ayrıca Tevfik İleri, İstanbul'u ikinci Kâbe yapacaklarını, her fabrika bacasının yanında bir minare yapacaklarını belirtmiş ve bu hususta "Mabetsiz Şehir" unvanına sahip olan başkent Ankara'ya Kocatepe Camii'nin temellerini bu dönemde atmışlardır.

24 Ahmet Naki Yücekök, Türkiye'de Örgütlenmiş Dinin Sosyo-ekonomik Tabanı, Sevinç Matbaası, Ankara 1971, s. 51.

25 Erik JanZürcher, Modernleşen Türkiye’nin Tarihi, İletişim Yayıncılık, 2008,s. 324. 


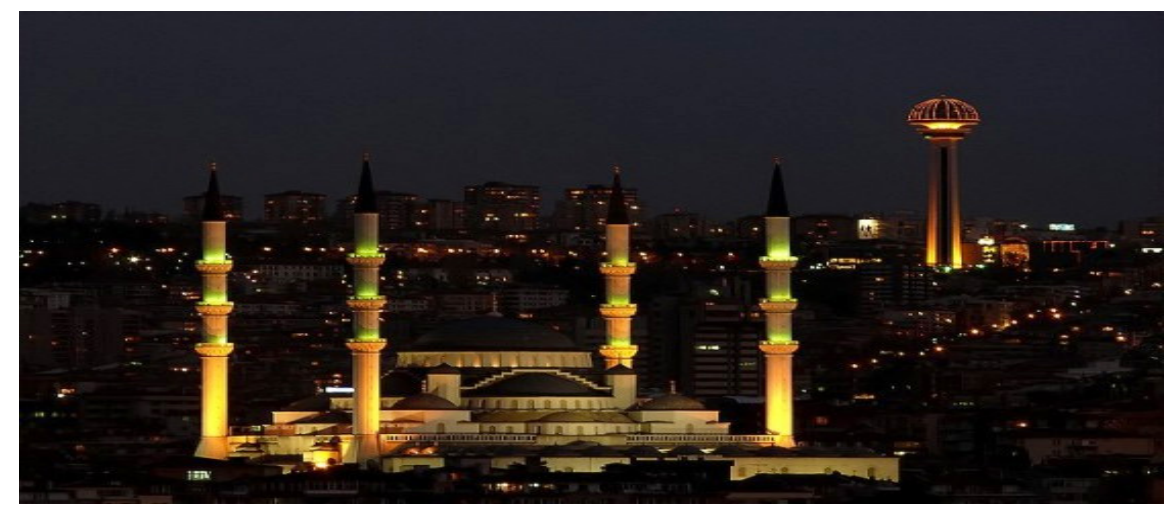

(Menderes'in fikir babası olduğu ve temeline ilk harcı koyduğu Kocatepe Camii)

Dini eğitimlerin (İmam Hatip Okullarının) daha nitelikli bir duruma getirilmesi için Menderes, Yüksek İslam Enstitülerinin açılması için büyük emek ve gayret sarf etmiştir. Bu husus ile ilgili taleple kendisini ziyarete gelen heyete düşüncelerini şu şekilde ifade etmiştir:

"Hayatım pahasına bile olsa imam hatip okullarının yüksek kısmını açacağım. Eğitim - öğretim sahasında din konusuna önem veremiyoruz. Bunu laikliğe aykırı sayıyorlar. Milletimizin mayası ahlâktır, imandır, İslâm'dır. Eğer biz bugün ayaktaysak aksakallı bir dedenin kucağında büyüdüğümüz için ayaktayız."

Türk hacılarının uzun bir fasılanın ardından ilk kez hacca gitmeye başladığı 1950 yılında yaklaşık dokuz bin kişi hacı olur. DP toplumun istekleri doğrultusunda dini serbest bırakmakla birlikte dini komünizmin panzehri olarak da görmüş ve kullanmıştır. Menderes'e göre ${ }^{26}$ manevi değerlerle harmanlanmamış gençlik, teknik ve bilim ile ne kadar donatılırsa donatılsın, bağımsız ve özgür devlet için bir güvence oluştur(a)mayacaktır. Bundan ötürü genç neslin manevi değerlerle harmanlanmas1/yetiştirilmesi elzemdir.

Türk müziğine 1950'de yapılan seçimlerden sonra radyoda ve okullarda ağırlık verilmiştir. Zira o vakitlere değin müzik yayınlarında ağırlıklı olarak batı müziğine yer verilmiştir. 1950 seçimlerinden sonra dönemin alaturka sanatçılarının bestelerinin sesleri de duyulmaya başlanmıştır. Türk toplumu tarafından "Feraya" ve "Kırmızı Gülün Alı Var” şarkıları ilk defa duyulmuştur ${ }^{27}$.

Hat, tezhip, seramik, heykel, resim, mimarlık ve şiir gibi güzel sanatlar alanında kurumsallaşma adına önemli bir aşama olan ve şu anda Mimar Sinan Üniversitesi'nin temeli Güzel Sanatlar Akademisi bu dönemde (1959) kurulmuştur. Özel tiyatro ve sanat galerilerin de (Maya) açıldı̆̆ bu dönemde, Bülent Ecevit' in ilk kez bahsettiği soyu resim sanat çalışmaları (Neşet Günel ve İbrahim Balaban'ın başını çektiği Siyah Kalem Grubu) yapıldığı görülmektedir. Sinema alanında ise Lütfi Ömer Akad'ın "Vurun Kahpeye-1949” ve “Kanun Namına-1952” filmleri çevrilirken Osman F. Sedan ise çok sayıda yerli filmi çevirdiği görülmektedir. Ancak bu dönemde ABD ve Fransız sinemasından da ciddi çevirilerin yapıldığı görülmektedir.

Menderes'in İstanbul'a her geldiğinde ziyaret ettiği Eyüp Sultan Türbesi, türbe yakını ve

26 Nuran Dağlı ve Belma Aktürk. Hükümetler ve Programları (1920 - 1960), TBMM Yayınları, Ankara 1988,s. 176.

27 Şevket Çizmeli, Menderes:Demokrasi Ylldızı?, Arkadaş Yayınevi, Ankara 2007, s. 285. 
camiinin restore edilmesinden sonra açılışını yapan Adnan Menderes "Mazisine, ecdadina, onların bıraktı̆̆ paha biçilmez değerli eserlere hayrı olmayan bir cemiyetin kendisine de hayrı olmaz"şeklinde ifadeler kullanmıştır ${ }^{28}$.

DP iktidarı (1950-60) döneminde İstanbul'a özel bir anlam atfetmiştir. İstanbul'u Türk tarihinin somutlaşmış merkezi olarak tasvir etmişsir. "İstanbul'u İslâm Dünya'sının ikinci Kâbe'si yapacaklarını" ifade eden Menderes bu hususu İstanbul'un fethinin 500. Y1lının kutlanması için önemli hazırlıklar yapmış ve İslam ülkelerinin devlet başkanlarını davet etmiştir. İstanbul'un imarı ile ilgili 26 Şubat 1957'de Menderes "istanbul'un imarı mevzuu adeta bir zafer alayının hikâyesidir. İstanbul'u bir kere daha fethedeceğiz"şeklinde iddialı bir beyanat vermiştir ${ }^{29}$.

DP döneminde İstanbul'un modern bir görünüme kavuşturulması için Millet ve Vatan Caddeleri ve Sahil Yolu yapılmış, Yıldız Porselen Fabrikasının ambarlarından, bodrumlarından değerli, nadide ve naif güzellikte olan kalıplar çıkartılmış ve bu fabrika yeniden üretime başlatılmıştır 30. Fakat bu hususta DP İstanbul'un tarihi dokusuna zarar verdiğine/bozduğuna dair iddialar ve eleştiriler yöneltilmiştir. Bu eleştirilerin temel nedeniyse Sur içerisinde yapılan yol (Sahil Yolu ve Vatan, Millet Caddesi gibi) çalışmaları sonucunda yıkılmış olan, tahrip edilen tarihi eserlerdir. Bu eleştirilere karşı İstanbul Belediye Başkanı Mümtaz Turhan, 28 Mart 1958'de Belediye Meclisinin olağan toplantısında şu açıklamaları yapmışıır ${ }^{31}$.

"Gücümüzün tükendiği bir anda seslenişimize, imdadımıza bir Mesih gibi, bir Hızır gibi koşan biri çıktı. Bu, hepimizi hizmete yönelten başvekilimiz Adnan Menderes'tir. Camiler onun senakârıdır, surlar onun dualarıdır, caddeler ve bulvarlar onun hamleli işaretlerine müştaktır açıklamasında bulunmuştur."

Devlet Bakanı Hüseyin Celal Yardımcı şöyle cevap vermiş̧tir ${ }^{32}$ :

Memleketimizde şimdiye kadar cami yapımı ve tamiri amacıyla 795 adet dernek kurulmuştur, 1952 malî y1lı içinde Vakıflar Genel Müdürlüğü bütçesinden bu derneklerin 63'üne 32.688 lira yardım yapılmıştır, 1953 yılı Vakıflar bütçesine «dernekler ve köyler tarafından inşa veya tamir ettirilecek camilere yardım» için ayrıca 500.000 lira ödenek konulmuştur, bu fasıldan bu güne kadar 161 derneğe 297.459 lira, 289 köy camiine de 114.350 lira yardım yapılmıştır. (...) Ankara belediye hudutları içinde 30 yıl önce (1953'ten önce) 90 cami ve mescit varken 1935 yllında kabul edilen cami ve mescitlerin tasnifine dair 2845 sayılı kanun uyarınca bunlardan 29'u kadro dışına çıkartılmış, geçmiş yıllarda bu 29 camiden 14'ü satılmış, 9'u yıkılarak arsa haline getirilmiş, 3'ü akara çevrilmiş, 3'ü de istimlâk edilmiştir, geri kalan ve halen faal olan 61 kadar cami ve mescide ilave olarak son yıllarda halk tarafindan yaptırılan 11 cami ile birlikte bugün Ankara belediye hudutları dâhilinde 72 cami ve mescit bulunmaktadır.

1. DP iktidarı (1950-60) dönemlerine yoğun bir dernekleşme süreci yaşanmıştır.

28 Mükerrem Sarol, Bilinmeyen Menderes, Kervan Yayınları, Ankara 1983, s. 305.

29 Şevket Çizmeli, Menderes:Demokrasi Yıldızı?, Arkadaş Yayınevi, Ankara 2007, s. 573.

30 Mükerrem Sarol, Bilinmeyen Menderes, Kervan Yayınları, Ankara 1983, s. 309.

31 Şevket Çizmeli, Menderes:Demokrasi Ylldızı?, Arkadaş Yayınevi, Ankara 2007, s. 576.

32 TBMM TD, 1953, s. 185-186. 
Derneklerin konusu ve sayısı şu şekilde belirtilmiştir ${ }^{33}$ :

2. 1946'ya kadar sosyal yardımlar ile ilişkili 46 dernek kurulmuştur. 1946-1950 yılları arasında ise bu sayı 208' e 1950-1960 dönemde ise sosyal yardımlar ile ilişkili dernek sayısı 638' çıkmıştır.

3. 1946 yılına kadar dini konularla ilgili yalnızca 8 dernek kurulmuştur. 1946-1950 arasında bu sayı 142, 1950-1960 yılları arasında ise bu sayı 4821'e çıkmıştır.

4. 1950 yılına kadar kültür alanında faaliyet gösteren dernek sayısı 285 iken 1950-1960 yılları arasında dernek sayısı 2511 olmuştur.

5. 1946 yılına kadar azınlıkların ve yabancıların kurmuş olduğu dernek sayısı 35 iken 1946-1950 arasında ise 75 olduğu, 1950-1960 yılları arasında ise 218' yükseldiği bilinmektedir.

Memur, esnaf, serbest meslek, işveren, spor, tarım gibi birçok alanda yoğun bir dernekleşme yaşanmıştır. Cemiyetler Yasasının (1946) çıkmasıyla birlikte dernekleşme faaliyetlerinin artığı her ne kadar görülse de 1950-1960 yılları arasında tüm alanlarda dernekleşme faaliyetlerinin zirve yaptığ́1 görülmüş̧ür. Özetle 27 yıllık tek parti döneminde ciddi bir bask1 göre kültürel faaliyetler DP iktidarında adeta patlama göstermişlerdir.

\section{Sonuç}

$\mathrm{Bu}$ çalışmanın sonucunda, DP'nin iktidara gelmesi ve on yıl aralıksız iktidarda kalması ve 27 Mayıs darbesiyle iktidardan düşürülmesinin esas sebebinin DP'nin kültürel faaliyetleri olduğu görülmektedir. Bu çalışmada varılan sonuçlar aşağıda maddeler halinde sıralanmıştır:

1. II. Abdülhamid'in devrilmesinden sonra (1909) iktidar boyutuyla yaşanan ciddi kültürel kırılmadan sonra 1950 yılında iktidara gelen DP'nin, 40 yıldır Batı kültürünün (Osmanlı hanedan1, müzik, siyaset dili, mimari, dernekler, dil, dini değerler, kıyafet, tarihi eserler, sinema...) karşısında sürekli mevzi kaybeden Anadolu kültürünü, Batı Kültürünün yanında (karşısında değil) ayağa kaldırdığı ve aynı masaya oturttuğu görülmektedir.

2. CHP bile bu anlamda, biz bu alanda hata yaptık diyerek halka ve DP'ye yakınlaşmıştır. CHP bile halktan gelen talepler ve DP'nin baskısı üzerine, türbeler ve din dersleri ve kültür alanında açılımlarda bulunmuştur.

3. Bu dönemde Anadolu Kültürüne has olan kültürel ögelerde canlanma görüldüğü gibi Batı ve Uzakdoğu kültüründe de canlanma görülmüştür. Bu nedenle kültürel alanda, kamu ve özel sektörde ciddi hareketlenmeler görülmüştür.

4. DP'nin iktidarda olduğu (1950-60) dönemde tarihi eserlere (özelikle İstanbul'da bulunan) ilgi artmış, tarihi eser restorasyonlarına hız verilmiştir. Cumhurbaşkanı Bayar, Fatih Sultan Mehmet'ten bu yana restore edilmeyen Rumelihisarı ve İstanbul Surlarının restorasyonunu başlatmış ve restorasyonu yakinen takip etmiştir.

5. DP'nin de kuruluşundan 27 Mayıs 1960 tarihindeki; dış destekli, askeri ve sivil azınlık karışımı bir Cunta Darbesine kadar on dört yı1lık boyunca kansız bir Anadolu karşı

33 Ahmet Naki Yücekök, Türkiye’de Örgütlenmiş Dinin Sosyo-ekonomik Tabanı, Sevinç Matbaası, Ankara1971,s. 109. 
devrimi olarak görülmektedir. Halk, ulaşım ve iletişim yaygınlaşmasıyla hem bastırılmış kültürel değerlerine dönmüş hem de yoğun bir şekilde Amerikan ağırlıklı Batı kültürünün etkisinde kalmıştır.

6. Aynı şekilde kültürel yakınlık içinde bulunduğumuz Müslüman ülkelere yönelik olarak DP, başta Ortadoğu (Bağdat Paktı) ilk kez siyasi yakınlaşma içinde bulunmuştur.

7. DP'den sonra gelen AP, MSP, ANAP ve AK Parti gibi muhafazakâr partiler, kendilerini kültürel anlamda DP'nin varisi ve tarihin devamı olarak görmüşlerdir. Bu anlamda akla gelen en önemli kişi ise Adnan Menderes'tir.

\section{Kaynakça}

Ahmad, Feroz. Modern Türkiye'nin Oluşumu. İstanbul: Sarmal Yayınları, 2005.

Aydemir, Şevket Süreyya. İkinci Adam. Cilt III. İstanbul: Remzi Kitapevi, 1968.

Başar, Ahmet Hamdi. Yine Hayal Aleminde Uçuyorum. İstanbul: İstanbul Üniversitesi Yayınları, 2007.

Burçak, Rıfkı Salim. İdamların İ̧̧ Yüzü. Ankara: Demokratlar Kulübü Yayınları, 1979.

—. Yassıada ve Öncesi. Ankara: Çam Matbaası, 1977.

Cihangir, Feyullah. «Tek Parti İktidarından Çok Partili Döneme Türkiye ve Bediüzzaman'ın Siyasal Çizgisi.» Köprü Dergisi, 2004.

Çatalbaş, Serkan, ve Nurgün Koç. «Demokrat Parti Dönemi Kültür Politikaları 1950-1960.» Türk İslam Medeniyeti Akademik Araştırmalar Dergisi, 2016.

Çizmeli, Şevket. Menderes:Demokrasi Yıldızı? Ankara: Arkadaş Yayınevi, 2007.

Dağl1, Nuran, ve Belma Aktürk. Hükümetler ve Programlarl (1920 - 1960). Ankara: TBMM Yayınları, 1988.

Eraslan, Cezmi. «Atatürk’ten Sonra Türkiye İç Politikası.» Atatürk Araştırmaları Merkezi Dergisi, 2004.

Gedikoğlu, Şevket. Kemalist Eğilim İlkeleri, Uygulamaları. İstanbul: Erdini Matbaası, 1978.

İrem, Cemal Nazım. «Kemalist Modernizm ve Türk Gelenekçi-Muhafazakârlığının Kökenleri.» Toplum ve Bilim Dergisi, 1997: 52-99.

Karakuş, Emin. 40 Yllllk Bir Gazeteci Gözüyle İşte Ankara. Ankara: Hürriyet Yayınları, 1977.

Kumaş, Rahmi. CHP'nin Soyağacı. İstanbul: Çağdaş Yayınları, 1999.

Levendoğlu, Mazhar. Atatürk'ün Vasiyeti. İstanbul: Bahar Matbaası, 1968.

Lewis, Bernard. Modern Türkiye'nin Doğuşu. Ankara: Arkadaş Yayınları, 2009.

Mardin, Şerif. İslâmcllı", Cumhuriyet Dönemi Türkiye Ansiklopedisi. Cilt VII. İstanbul: İletişim Yayınları, 1995-1996.

Refik, İbrahim. Geçmişten Geleceğe Işıklar. İstanbul: Albatros Yayınları, 2000. 
Sarol, Mükerrem. Bilinmeyen Menderes. Ankara: Kervan Yayınları, 1983.

Sertel, Zekeriya. Hatırladıklarım (1905 - 1950). İstanbul: Yaylacık Matbaası, 1968.

Shaw, Standford J., ve Ezel Kural Shaw. Osmanlı Imparatorluğu ve Modern Türkiye. Cilt II. İstanbul: E Yayınları, 1983.

Sitembölükbaşı, Şaban. Parti Seçmenlerinin Siyasal Yönelimlerine Etki Eden Sosyoekonomik Faktörler. Ankara: Nobel Yayın Dağıtım, 2001.

Son Telgraf Gazetesi.3 Temmuz 1947.

Sükan, Faruk. Başbakan Adnan Menderes'in Meclis Konuşmaları, TBMM (1950/1960). Ankara: Kültür Ofset, 1992.

Şeyhanlıoğlu, Hüseyin. «Radyonun Demokratik Yaşamda ve Siyasetteki Etkisi: Demokrat Parti Dönemi (1950-1960).» Tarih ve Gelecek Dergisi, Aralık 2019: 805-818.

-. Türk Siyasal Muhafazakârlı̆̆ının Kurumsallaşması ve Demokrat Parti. Ankara: Kadim Yayınları, 2011.

-. Türkiye'nin Siyasal Hayatında Demokrat Parti. İstanbul: Kitapyurdu Doğrudan Yayınc1l1k, 2020.

Toker, Metin. Demokrat Partinin Altın Yılları (1950-1954). Ankara: Ofset Tipo Matbaacılik, 1990.

Turan, Ali Eşref. Türkiye'de Seçmen Davranışı Önceki Kırılmalar ve 2002 Seçimi. İstanbul: Bilgi Üniversitesi Yayınları, 2004.

Turan, Şerafettin. Türk Devrim Tarihi Çă̆daşlık Yolunda Yeni Türkiye. Ankara : Bilgi Yayınevi, 1999.

Yücekök, Ahmet Naki. Türkiye'de Örgütlenmiş Dinin Sosyo-ekonomik Tabanı. Ankara: Sevinç Matbaası, 1971.

Zürcher, Erik Jan. Modernleşen Türkiye’nin Tarihi. İletişim Yayıncılık, 2008. 